Litors r $\begin{array}{r}2017 \text { Volume 23(3): 549-565 } \\ \text { doi:10.3846/20294913.2017.1312629 }\end{array}$

\title{
MACROECONOMIC NOISE REMOVAL ALGORITHM (MARINER)
}

\author{
Marinko SKARE \\ Economics and Tourism, Juraj Dobrila University of Pula, Preradoviceva 1/1, Pula, 52100 Croatia \\ Received 06 January 2017; accepted 24 March 2017
}

\begin{abstract}
Standard econometric filters fail to extract explicit trend component from macroeconomic data series. Isolated cycles provide no economic interpretation of the extracted component. Adding new data to the sample (filtering) period results in instability of extracted components. This study proposes a new econometric filtering technique (MARINER) able to overcome known shortcomings in standard econometrics filters such as Hodrick and Prescott (1997), Baxter and King (1999), Christiano and Fitzgerald (2003). MARINER provides a practical tool for policy makers dealing with business cycles. It also provides economic interpretation (new theory) on causes and sources of business cycles elaborating on theories developed by Phillips (1962) and Škare (2010). MARINER decomposes GDP macroeconomic data series in trend (long term) and cycles (medium term) components using three year moving average recursive filtering method. Extracted cycles are defined as deviations from equilibrium GDP path (minimized output gap) caused by poor synchronization between monetary and fiscal policy. MARINER bridge the gap in the literature on measuring and causes of business cycles. MARINER can purpose as foundation for building a new, primer econometric filtering methods.
\end{abstract}

Keywords: business cycles, econometric filters, band-pass, moving average, MARINER, Golden triangle.

JEL: C22, C53, E32, E37, E63.

\section{Introduction}

Identifying underlying true signals from noise in macroeconomic data is crucial to macroeconomic forecasting. Special filtering techniques exists to separate trends from random noise in original data series. Standard filtering techniques rely on NBER business cycle definition Burns and Mitchell (1946) to "filter" (smooth, denoise) original economic data. Common filters in digital signal processing capture trends (low pass), business cycles (band pass) or irregular components (high pass) in economic time series data. Different businesscycle component extraction methods exist focusing on frequency and signal extraction

Corresponding author Marinko Skare

E-mail: mskare@efpu.hr 
issues. Such a practice resulted in a development of an mechanical view on the time series properties and trend and noise isolation. This is also a primary reason for abandoning wide usage of Burns and Mitchell (1946) in economic time series analysis. Frequency and signal extraction methods mainly focus on trend cycle decomposition forgetting the central question - what we want to measure.

A new econometric filtering techniques called MARINER (Macroeconomic noise removal algorithm) is developed to decompose the output series (GDP) in long term component (trend) and a medium-term component (business cycle) based on Phillips (1958, 1962), Burns and Mitchell (1946), Diebold and Rudebusch (1996), Škare (2010) business cycles theory. Proposed econometric filter offer economic interpretation for the extracted business cycle component and it is also robust to the issue of new data addition. Stability tests and forecasts tests show MARINER outperforms standard econometric filters used on the sample in this study.

Standard econometric filters such as Hodrick and Presscot (HP filter) (1997), simple moving average, exponential smoothing, Baxter and King (1999) (BK filter), Christiano and Fitzgerald (2003) (CF filter) are commonly used in filtering of macroeconomic data series. They are designed to extract trend (HP filter) or trend cycle components from the macroeconomic time series data. They are focused on isolating series components based on their spectral structures (within specified frequency band), i.e. moving average filters use moving average method to extract trend and cycle component. Band pass filters use power spectrum analysis to measure trends and cycles in macroeconomic time series. HP filter extracts the trend of the series by using specified smoothing parameter. HP it is among most used filters but often strongly criticized (Cogley, Nason 1995).

Past research on business cycles rely on a mechanical view on trend and cycle components from the macroeconomic data series without providing any economic interpretation on the extracted components. It seems that the same mechanical filtering techniques developed in econometric filters dominate over business cycle theory. Researchers are more focused on extracting trend, trend cycle or cycle components without providing any relevant economic interpretation for the same extracted components. Not only standard econometric filtering techniques lack to provide relevant economic interpretation of the components but also fail to determine the factors behind them. Although a large body of literature exists business cycles theories (Skare, Stjepanović, 2015) as well as methods for identifying business cycles (see Table 1) scientific studies linking the two are missing. To overcome this gap in the literature it is essential to develop a new filtering techniques able to provide relevant economic interpretation on the extracted business cycle components explaining the factors that cause it.

To address this issue, the purpose of this research is to develop a new econometric filtering technique called MARINER that will close the gap in the literature between measuring and explaining business cycles. More specifically, this research has two objectives:

1) to develop a new econometric filtering technique for extracting trend and cycle components separately based on business cycle theory developed by Phillips (1962) and Škare (2010) and provide a completely new view on the causes of business cycles and new definition of a business cycle; and 
2) explain the factors that are causing business cycles appearance and dynamics as well to provide a novel filtering technique superior in extracting trend component but also forecasting ability in relation to standard econometric filtering techniques.

Studies results generated from this research should broaden the body of literature in the field of econometric filters and business cycles theory and provide to policy makers a novel economic tool for designing efficient economic policies.

The remainder of the paper is structured as follows: First a literature review about measuring and explaining business cycles is presented. Next a conceptual and methodological framework used to develop a new filtering procedure (MARINER) is described. The finding are presented in Section 3 presenting the summary of study's research contribution, limitations and directions for further research.

\section{Literature review}

Phillips seminal contribution in his paper (1962) although widely neglected raise the central question in business cycle measuring techniques - when and why business cycles appear and what are the factors behind them. Phillips did not engage in the task of building a filtering technique for extracting the business cycle component but instead set up a ground for an economic interpretation of the business cycles and its causes. In his opinion, an empirical relationship between employment, inflation and growth exists. Lack of the quantitative behaviour of such a link results in setting inconsistent economic policy aim by policy makers and in the end, poorly designed economic policy. Final consequence of such policy framework is the appearance of economic agents "schizophrenic" behaviour on the market and harmful changes in economic activity (cycles). Phillips did not use the word cycle but his theoretical explanation in the paper pointed in that direction. In his paper, however Phillips did not offer any empirical evidence to support his thesis. Building on Phillips' work, Škare (2010) provides empirical background required to set up a new econometric filtering techniques developed in this paper.

Body of literature on the business cycles can be separated in two categories: one dealing with measuring the business cycles and other trying to explain business cycles. Close to the first but still outside the general body of literature on the subject are studies on econometric filters and macroeconomic time series smoothing techniques. Table 1 provide a summary of most important literature about business cycles.

Seminal papers of Mitchell $(1927,1913)$ define the basic idea of business cycles as fluctuations in aggregate economic activity setting the ground for future studies on the subject. Subsequent research (Nelson, Plosser 1982) concentrated more on the trend cycle component extraction (stochastic vs deterministic trend) leaving business cycles Mitchell's original economic interpretation. The issue of stochastic trend dynamics invokes the use of unit root tests and similar approach (Stock, Watson 1988) and detrending methods (Hodrick, Prescott 1997). This one is to become a most popular detrending methods in macroeconomic data mining although new studies strongly attack the validity of their approach (Hamilton 2016). Possible bias in (Hodrick, Prescott 1997) is particularly present when analyzing business cycles in former transitional countries (Rašić Bakarić et al. 2016) 
and others small open economies (Sodeyfi, Katircioglu 2016). Band pass filters developed by Baxter and King (1999), Christiano and Fitzgerald (2003) try to overcome the limitation in (Hodrick, Prescott 1997). Pollock $(2000,2016)$ propose to use a class of Butterworth filters (Butterworth 1930) to improve econometric extraction methods.

Another strain of literature focus their effort to explain the factors behind extracted business cycles. Technological shocks prevail in the literature as most important factor behind cycles (Prescott 1986) with endogenous components within (Norrbin 1993) or monetary aggregates (Evans 1992). Studies on total factor productivity close on the gap between total factor productivity and technology shocks, their importance in business cycles and associated economic growth (growth cycles theories), see (Zarnowitz 1992a, 1992b). Studies direct on factors of production, capital (Basu 1996), labor (Burnside et al. 1993), income (Jaimovich, Floetotto 2008). Galí (1999) explore the link between technology shocks and

Table 1. Body of most important literature on measuring business cycles and factors causing business cycles

\begin{tabular}{|c|c|c|c|}
\hline $\begin{array}{c}\text { Studies on } \\
\text { measuring business } \\
\text { cycles }\end{array}$ & Results & $\begin{array}{l}\text { Studies on causes } \\
\text { of business cycles }\end{array}$ & Results \\
\hline $\begin{array}{l}\text { (Burns, Mitchell } \\
\text { 1946) }\end{array}$ & $\begin{array}{l}\text { Typical fluctuations in } \\
\text { economic activity }\end{array}$ & $\begin{array}{l}\text { (J. M. Keynes 1936) } \\
\text { (Dixit, Stiglitz 1977) }\end{array}$ & $\begin{array}{l}\text { Fluctuations in } \\
\text { aggregate demand } \\
\text { causes cycles } \\
\text { Monetary shocks }\end{array}$ \\
\hline (Singleton 1988) & $\begin{array}{l}\text { Using HP filter } \\
\text { approach to define } \\
\text { cycles }\end{array}$ & (Nelson, Plosser 1982) & $\begin{array}{l}\text { Technology shocks } \\
\text { impact on cycles }\end{array}$ \\
\hline (King et al. 1991) & $\begin{array}{l}\text { Real business cycle } \\
\text { model }\end{array}$ & (Prescott 1986) & $\begin{array}{l}\text { Uncertainty and } \\
\text { technological shocks } \\
\text { impact }\end{array}$ \\
\hline $\begin{array}{l}\text { (Zarnowitz 1992a, } \\
\text { 1992b) }\end{array}$ & $\begin{array}{l}\text { Cycles as deviations } \\
\text { from long term trend }\end{array}$ & (Norrbin 1993) & $\begin{array}{l}\text { Total factor } \\
\text { productivity }\end{array}$ \\
\hline $\begin{array}{l}\text { (Cogley, Nason } \\
1995)\end{array}$ & $\begin{array}{l}\text { Measuring cycles using } \\
\text { HP approach }\end{array}$ & (King et al. 1991) & $\begin{array}{l}\text { Growth and cycles } \\
\text { correlated }\end{array}$ \\
\hline (King, Rebelo 1999) & RBC model & $\begin{array}{l}\text { (Christiano, Eichenbaum } \\
\text { 1992; Evans 1992; Kim, } \\
\text { Loungani 1992) }\end{array}$ & $\begin{array}{l}\text { Fiscal shocks impact } \\
\text { Oil price and } \\
\text { technology shocks }\end{array}$ \\
\hline (Baxter, King 1999) & $\begin{array}{l}\text { Spectral analysis of } \\
\text { time series (cycles) }\end{array}$ & $\begin{array}{l}\text { (Braun 1994; McGrattan } \\
\text { 1994) }\end{array}$ & Fiscal policy shocks \\
\hline $\begin{array}{l}\text { (NBER Committee } \\
\text { 2012) } \\
\text { (Hodrick, Prescott } \\
\text { 1997) } \\
\text { (Diebold, Rudebusch } \\
\text { 1996) }\end{array}$ & $\begin{array}{l}\text { Peak and trough } \\
\text { components } \\
\text { Removing short term } \\
\text { fluctuations } \\
\text { Economic series } \\
\text { comovement and } \\
\text { regime switching } \\
\text { economy }\end{array}$ & $\begin{array}{l}\text { (Bernanke 1983; Bernanke } \\
\text { et al. 1999; Burnside } \\
\text { et al. 1996), (Rotemberg, } \\
\text { Woodford 1996) } \\
\text { (Ramey, Shapiro 1998), } \\
\text { (Galí 1999), (King, Rebelo } \\
\text { 1999), (Baxter, King 1999; } \\
\text { Finn 2000; Fisher 2004) }\end{array}$ & $\begin{array}{l}\text { Monetary shocks } \\
\text { Government spending } \\
\text { shocks } \\
\text { Oil shocks } \\
\text { Government spending } \\
\text { shocks } \\
\text { Technology shocks } \\
\text { Fiscal shocks }\end{array}$ \\
\hline
\end{tabular}

Source: Author's review. 
business cycles with structural change being another important factor behind them (Punzo 2015). First to point on a possible link between macroeconomic policy efficiency and cycles were Stock and Watson (2003) and Romer (1999). However, the synchronization issue between fiscal and monetary policy is not addressed in their studies nor the possible link between employment, inflation and growth. These problems are addressed in this study. Fluctuations in aggregate demand were observed by Keynes (1936) as sources of fluctuations in economic activity.

\section{The new filtering procedure - developing (MARINER) algorithm}

This section elaborates the framework for developing Macroeconomic Noise Removal Algorithm (MARINER). In MARINER development, special attention was given on the issue what we try to measure and to the definition (characteristics/properties) of the component we measure. In that sense, MARINER is more closely connected to the Burns and Mitchell (1946), Diebold and Rudebusch (1996) research and their seminal contribution to the business cycle definition problem. However, theoretical background behind MARINER is not even remotely linked to Burns and Mitchell (1946) vision of business cycles. For the empirical application, developing a new filtering procedure called MARINER business cycles definition developed by Phillips (1962) and Škare (2010) were adopted in this study.

Phillips (1962) argue business cycles are the result of the issues policy makers face in designing appropriate economic policies due to the lack of quantitative knowledge on how the system works. Phillips was suggesting that lack of quantitative knowledge (empirical relations) between employment, inflation and growth prevent policy makers in setting up optimal economic policy framework. Consequently, applying inefficient economic policies results in economic agents schizophrenic behaviour giving space to business cycle appearance.

Developing on the construction of Phillips (1962), Škare (2010) propose empirical version of the Phillips' ideas in the form of the Golden triangle theory. He identifies golden (equilibrium) points between unemployment, inflation and output based on identified empirical relationship between them. Derived equilibrium GDP shows the long-term movement in the GDP series (trend). Based on his calculation and theory, a MARINER algorithm for separating GDP trend from the noise (business cycle component) is proposed.

Deviation from equilibrium GDP as defined in Škare (2010) represent the business cycle component (in his research Škare defined the equilibrium value of GDP not mentioning business cycles). Business cycles therefore are defined building on research of Phillips (1962) and Škare (2010) as temporary fluctuations in economic activity arising from policy adjustments in time and magnitude resulting in regime switching from "bad states" (low synchronization in comovement between unemployment, inflation and output) to "good states" (high synchronization in comovement between unemployment, inflation and output). These temporary fluctuations vary across the countries (in time length and scale) depending on the policy makers' ability to quickly adjust the economy using knowledgeable policy adjustments. Each regime phase, thus depends solely on the policy makers' ability to make the system stable. Failing to meet timely and appropriate corrective movements will produce unstable economic 
system dominated by regular cyclical fluctuations (business cycles).

MARINER isolates business cycles estimating unobserved time trend for the GDP series following Škare (2010). Škare (2010) shows that when there is high synchronization in comovement between unemployment, inflation and output actual GDP is close to potential. Following this reasoning business cycles can be defined as temporary deviations from equilibrium GDP (equal to potential GDP when perfect synchronization in economic policy exists). MARINER decomposes the GDP time series $\left(y_{\mathrm{t}}\right)$ into the underlying trend component $\left(g_{t}\right)$ following Harvey (1990). Remaining fluctuation in the time series represent fluctuations (business cycles) $\left(c_{t}\right)$.

$$
y_{t}=g_{t}+c_{t} .
$$

Standard filtering time series techniques assume the trend (underlying growth, signal) component is non-stationary (unit root) while MARINER extracts variance non-stationary deterministic time trend signal. The deterministic trend view in this model assume transitory shocks (inadequate economic policy regimes) cause long-run economy deviation from the equilibrium path as defined in the Golden triangle theory Škare (2010). MARINER algorithm takes the form of the two side recursive 3 point moving average filter:

$$
\begin{aligned}
& y_{t}=\frac{1}{M} \sum_{j=-(M-1) / 2}^{(M-1) / 2} x[i+j] ; \\
& y_{(t)}=y_{(t-1)}+x_{(t+p)}-x_{(t-q)},
\end{aligned}
$$

where $p=(M-1) / 2$ and $q=p+1$ with $\mathrm{M}=$ moving average window (in this case $M=$ 3). MARINER decomposes the observed GDP time series in trend (growth) and cyclical (business cycles) component. The trend component follows the assumption that trend does not have to be smooth as maintained by Harvey (1990) as opposed to Kendall (1976). The cyclical component $c_{(t)}=y_{(t)}-g_{(t)}$. To test the efficiency of the proposed algorithm we follow the approach of testing MARINER in highly volatile conditions (macroeconomic instability) against other standard filtering tools: Hodrick and Presscot (HP filter) (1997), simple moving average, exponential smoothing, Baxter and King (1999) (BK filter), Christiano and Fitzgerald (2003) (CF filter). For the purpose of improving robustness in testing the algorithms we select an economy with large macroeconomic instabilities and time series breaks (shifts) using GDP annual data for Croatia 1950-2009 from the Croatian central statistical office database. The sample end-point is the year 2009 since in the post period Croatian economy registered a sharp and long lasting decline (almost 7 years). Since Hodrick and Presscot (1997) filter and moving average (MA filter), exponential smoothing suffer from end-point cyclical component behavior issue data after 2009 are not used to preserve filter comparison robustness. Unlike the HP version of the moving average filter that extracts the trend solving the minimization problem $\left(y_{t}\right)$ deviations from $\left(g_{t}\right)$, MARINER minimize deviations of actual $\left(y_{t}\right)$ from potential $\left(y_{t}\right)$. Original GDP series is smoothed using recursive 5 point moving average of the equilibrium GDP series as defined in Škare (2010). Since equilibrium GDP series is defined as a series that minimizes the deviations of actual GDP from potential, MARINER extracts underlying trends in the GDP data. MARINER 
in relation to other similar decomposition filters (is beyond statistical technique) based on a real economic theory (Golden triangle) reflecting economic reality. Cycle is derived as actual gap between real GDP and potential GDP (minimum output gap) resulting from poor economic policy synchronization (regime changes).

Figure 1 display the results of applying the MARINER filter to Croatian gross domestic product time series.

The graph show the extracted underlying trend behind the Croatian gross domestic product time series. Many spikes in the series are visible due to the turbulent economic history of Croatia as a former socialist economy. Graphical comparison for the filters (extracted trend) comparison with actual data for Croatian GDP 1950-2009 is shown is Figures 2 and 3.

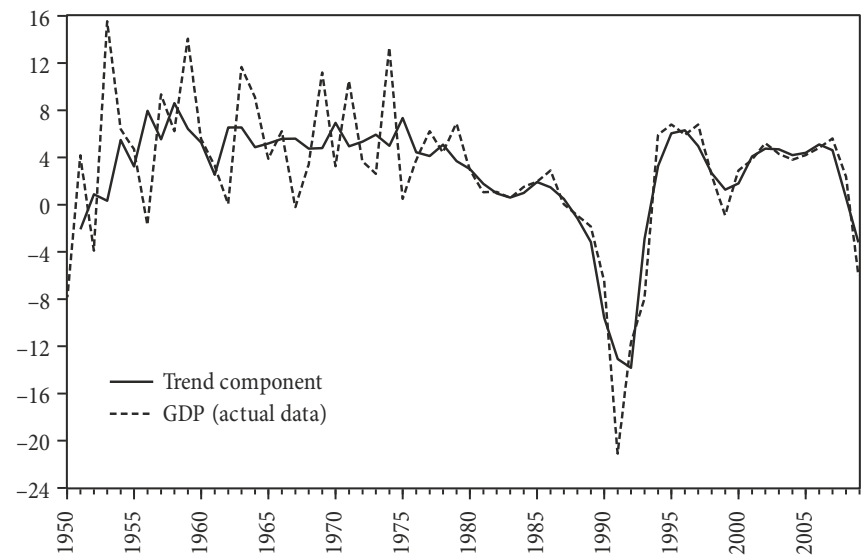

Fig. 1. MARINER filter trend component extraction (Croatian gross domestic product) Source: Author's calculations.

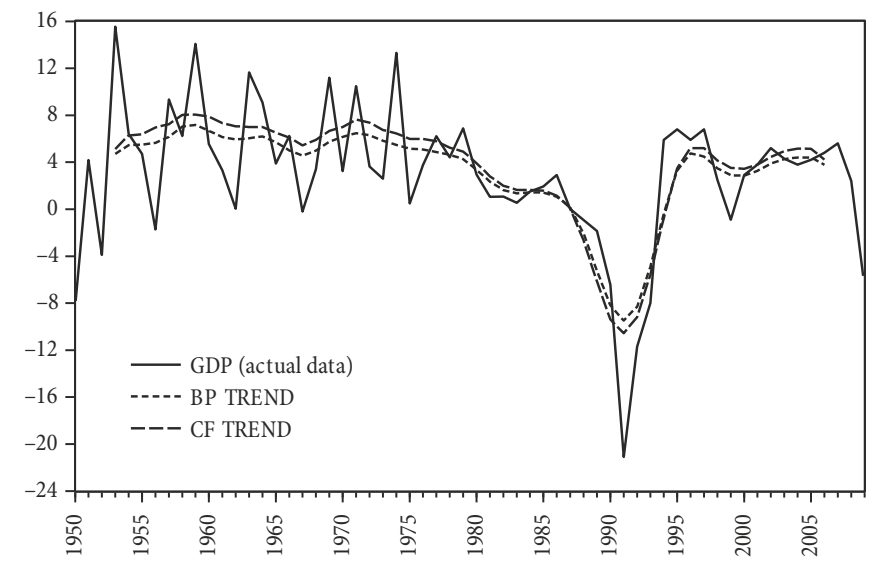

Fig. 2. Filter comparisons for extracted trend component in relation to actual GDP data (Croatia 1950-2009) Source: Author's calculations. 
Graphical comparison of the filters used for trend extraction compares extracted trend figures to actual GDP data to isolate trend that provides most robust approximation for long-run GDP Harvey (1990). From the Figures 2 and 3 is visible that the MARINER filter isolate the trend that best fits the actual GDP data. HP filter completely miss to identify turning points in the GDP series while BK and CF filter isolate the WAR (1990-1995) shock in the data. MARINER not only accurately extracts 1990 and 2008 crisis but also intermittent shocks due to high macroeconomic volatility during the central planning system (monetary and exchange rate policy shocks). Graphical comparison shows that MARINER performs better giving more robust trend extraction in relation to other standard data filters. Isolated smoothed trend obtained using HP, BK and CF filters get a match on fitting macroeconomic less volatile data but fail to perform better facing large volatility in macroeconomic data (such as used in this study). Decomposition of the GDP data using MARINER filter is visible on Figure 4.

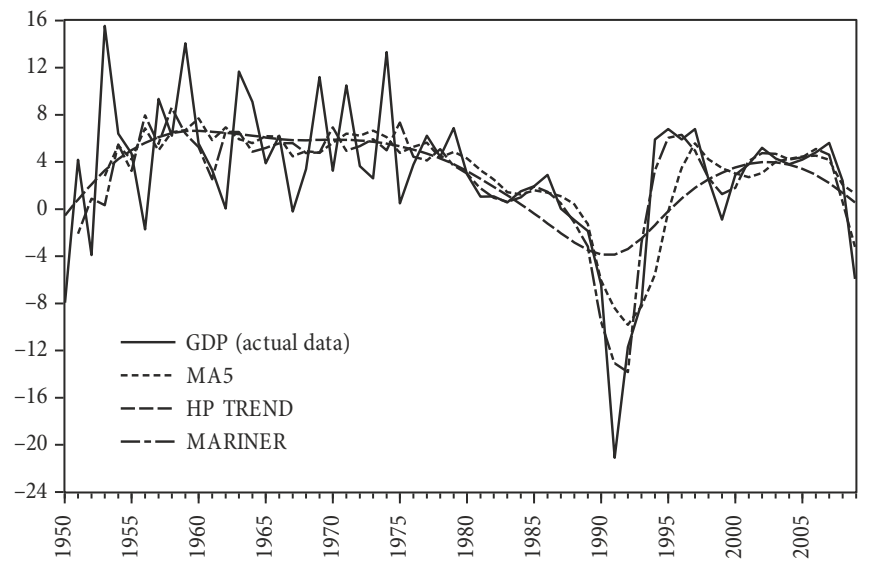

Fig. 3. Filter comparisons for extracted trend component in relation to actual GDP data (Croatia 1950-2009)

Source: Author's calculations.

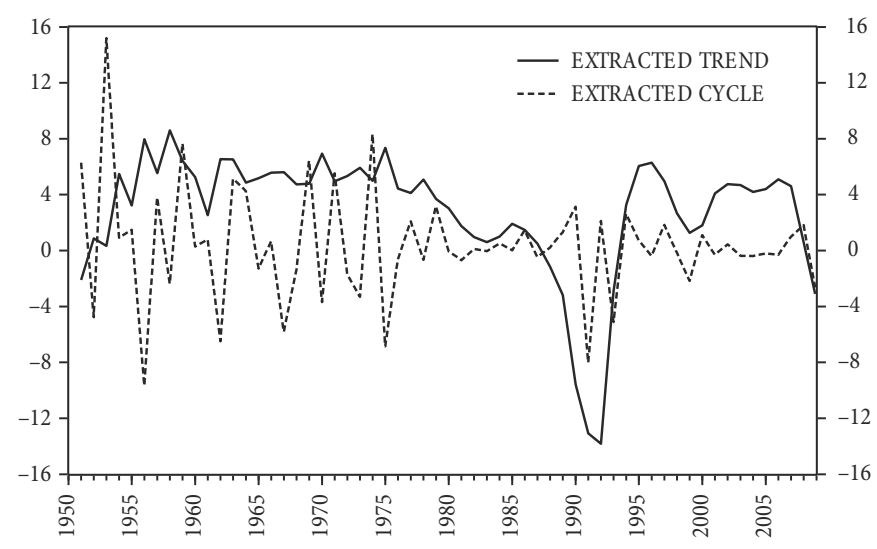

Fig. 4. GDP decomposition on trend and cycle series (Croatia 1950-2009) Source: Author's calculations. 
Just looking at the Figure 4, one can see the difference between standard filters for macro-data. The cycle series isolated using MARINER is less volatile in comparison to cycles isolated by other filters in Figures 5 and 6 . The reason is that while standard filters for macro data try to isolate business cycles frequency in accordance with general theory (between 6-32 quarters) MARINER isolates actual cycles (minimizing output gap). Critics on standard filters for macro data specially holds for Croatia. Business cycles in Croatia did not followed NBER definitions but were more frequent and less prominent at a point in time. In general, today business cycles are more prolonged and more volatile that was the case in the last century. Minimizing the output gap (this is the theory behind MARINER) has advantage over filtering techniques trying to isolate hypothetical lowhigh frequencies (business cycles frequencies) using moving averages or band pass filters.

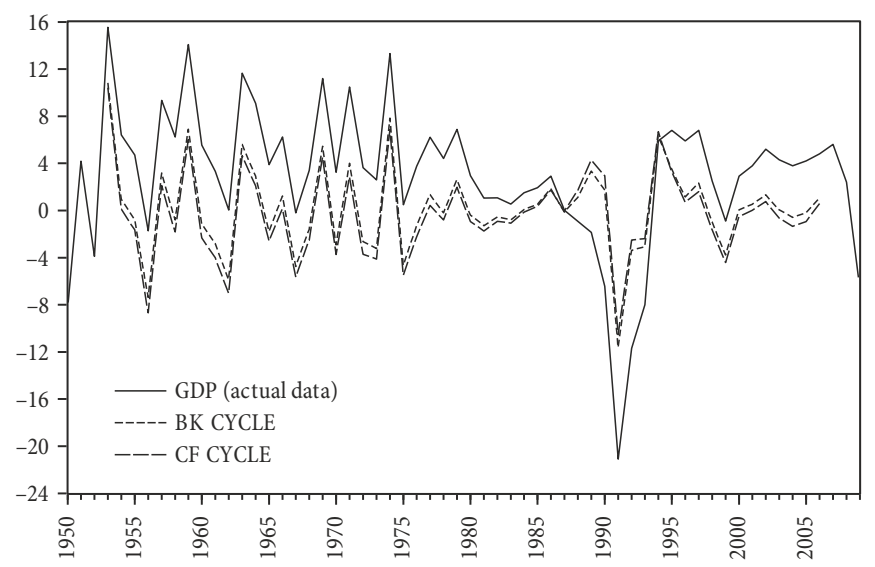

Fig. 5. Filter comparisons for extracted cycle component in relation to actual GDP data (Croatia 1950-2009) Source: Author's calculations.

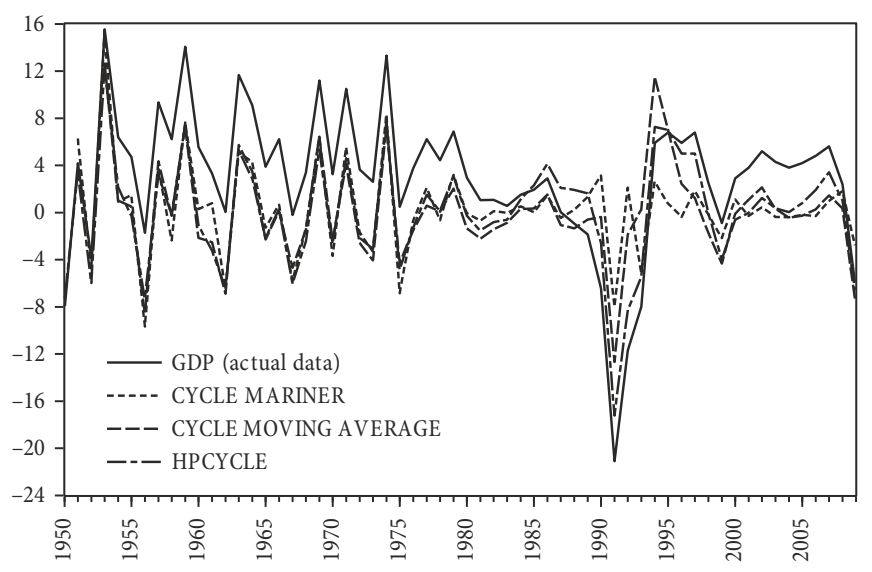

Fig. 6. Filter comparisons for extracted cycle component in relation to actual GDP data (Croatia 1950-2009)

Source: Author's calculations. 
Figures 2-6 show MARINER is more efficient in comparison to other filters in extracting trend and cycle component. Stability test for the filters used and end of the sample tests when adding new data to the series also support these findings (not presented here).

\section{Results}

In this paper, we decompose the GDP time series for Croatia 1950-2009 into a long-term component (trend), business cycle component (medium) and short term component (seasonal variation and measurement errors). The long term extracted component in this study in contrast to other filtering techniques rely on strong economic theory and interpretation. The extracted long term component gives a clear picture of possible future movements in Croatian GDP in the long-run satisfying Harvey (1990) trend definition. Instead of extracting a trend cycle component as general methods do, MARINER extracts a trend component (free of a business cycle component) which is still an issue for applied econometrics discipline. General HP, CF and BK models assume technology shocks and other types of exogenous, endogenous shocks. MARINER brings into the discussion the problem of macroeconomic policy synchronization as source of business cycle in an economy. Poorly synchronized macroeconomic policy (fiscal and monetary) can results in economic agents irrational behaviour leading to business cycles in the economy not just in the short run. Therefore, short run cycles arise from fiscal and monetary shocks turning in accumulated, long run permanent shock and not to disappear as economy returns to equilibrium. Both fiscal and monetary policy in literature appear as transitory components having a short run effect on output. Using MARINER to separate trend movements from fundamental business cycle we can observe that indeed the trend movement are in fact caused by changes in transitory components. Transitory components changes in fact have long term impact on GDP through inflation and unemployment expectations over a very long time. Policy regimes changes are the fundamental cause of business cycles in an economy.

Table 2 compare the models fit using extracted trend-cycles components using HP, CF, BK, MA(5) and MARINER (trend component) models.

From Table 2 we can see that MARINER outperforms HP, CF, BK and MA(5) filters fitting the model best using standard AIC (Akaike criterion), (Akaike 1974). MARINER

Table 2 Best model fit using extracted (trend), trend-cycles components with actual GDP as dependent variable

\begin{tabular}{lccccc}
\hline $\begin{array}{c}\text { Variable/Parameter } \\
\text { (dependent variable GDP) }\end{array}$ & HP & CF & BK & MA(5) & MARINER \\
\hline constant & -0.20 & -0.30 & -0.29 & 0.24 & 0.15 \\
\hline trend-cycle component & $1.12^{\star * *}$ & $0.94^{* * *}$ & $1.09^{* * *}$ & $0.86^{* * *}$ & $1.02^{* * *}$ \\
\hline Adjusted $\mathrm{R}^{2}$ & 0.33 & 0.52 & 0.53 & 0.34 & 0.55 \\
\hline AIC & 6.04 & 5.65 & 5.63 & 6.00 & 5.67 \\
\hline Durbin-Watson & 1.66 & 1.90 & 1.92 & 1.32 & 1.65 \\
\hline
\end{tabular}

Source: Author's calculations. 
also score the largest adjusted $\mathrm{R}^{2}$ value of 0.55 underlying that $55 \%$ of movement in actual GDP data can be explained by extracted trend (permanent component). Band pass filters performs better in relation to HP filter and moving average filters. Following Harvey (1990) that best trend approximation of the series (extracted trend component) is the one that gives the best indication of future long term movements of the series itself. For this purpose, we perform a set of forecast evaluation tests to see which of the extracted trend (trend-cycle) components gives better approximation of the future long term movements of Croatian output. We use Diebold-Mariano test (2002) with the test results presented in Table 3 based on the models fit in Table 2.

Table 3 Diebold - Mariano One-Step Test for the Forecasted GDP Series Using HP, CF, BK, MA vs MARINER

\begin{tabular}{lcccc}
\hline \multicolumn{1}{c}{ Test statistics (F-stat) } & HP & CF & BK & MA(5) \\
\hline Absolute error & $0.68(0.51)$ & $0.46(0.66)$ & $0.34(0.73)$ & $1.32(0.21)$ \\
\hline Squared error & $1.09(0.30)$ & $0.75(0.47)$ & $0.53(0.61)$ & $1.51(0.16)$ \\
\hline
\end{tabular}

Conclusion: Compared models give similar forecast predictive accuracy

Source: Author's calculations.

From Table 2, we can see that MARINER forecast compared to other models fit (HP, $\mathrm{CF}, \mathrm{BK}, \mathrm{MA}$ ) performs the best. However, the null hypothesis under the Diebold-Mariano test is not rejected for the competing predictions, i.e. between models forecast accuracy is not statistically significant. Test results show that forecasts from the compared models have similar predictive accuracy. Possible issues arise when using Diebold-Mariano test (small sample size, serially correlated loss differentials) as noted in Harvey et al. (1997) and Clark and McCracken (2001). To check the Diebold-Mariano test results we use a set of forecast tests for each individual model forecast (Table 3) under different evaluation statistics RMSE, MAE, MAPE, SMAPE, Theil U1, Theil U2.

Table 4. Forecast evaluation performance for HP, CF, BK, MA(5), MARINER using evaluation statistics

\begin{tabular}{lcccccc}
\hline \multicolumn{1}{c}{ Forecast } & RMSE & MAE & MAPE & SMAPE & THEIL U1 & THEIL U2 \\
\hline HP & 2.97 & 1.88 & 63.0 & 63.6 & 0.39 & 0.40 \\
\hline CF & 1.99 & 1.49 & 68.7 & 43.9 & 0.24 & 0.43 \\
\hline BK & 1.90 & 1.43 & 67.4 & 42.8 & 0.23 & 0.42 \\
\hline MA(5) & 2.83 & 2.10 & 84.9 & 64.2 & 0.36 & 0.50 \\
\hline Simple mean & 2.02 & 1.49 & 66.6 & 44.8 & 0.25 & 0.41 \\
\hline Simple median & 1.97 & 1.47 & 67.7 & 43.6 & 0.24 & 0.42 \\
\hline MSE ranks & 2.02 & 1.49 & 66.6 & 44.8 & 0.25 & 0.41 \\
\hline MARINER & 1.76 & 1.31 & 68.9 & 42.6 & 0.19 & 0.49 \\
\hline
\end{tabular}

Notes: $\mathrm{RMSE}=$ root mean square error, $\mathrm{MAE}=$ mean absolute error, MAPE $=$ mean absolute percent age error, SMAPE = symmetric mean absolute percentage error, THEIL = Theil inequality coefficient, bold $=$ best forecast performance.

Source: Author's calculations. 
Table 4 results show MARINER by RMSE, MAE, SMAPE, THEIL U1 evaluation statistics exibit best forecast performance from all tested forecast models and averaging methods. Future long term movements of Croatian GDP can be best approximated by using MARINER algorithm. Results from Table 3 are checked using forecast encompassing test of Chong and Hendry (1986) and modified by Timmermann (2006). Test results are displayed in Table 5. Results show the null of average forecast as more accurate in relation to a single forecast is rejected for HP and MARINER.

Table 5. Forecast evaluation performance for HP, CF, BK, MA(5), MARINER using forecast encompassing test

\begin{tabular}{ccc}
\hline Forecast test & F-stat & F-prob \\
\hline HP & 7.74 & 0.02 \\
\hline CF & 2.28 & 0.18 \\
\hline BK & 1.95 & 0.22 \\
\hline MA(5) & 0.70 & 0.61 \\
\hline MARINER & 6.16 & 0.02 \\
\hline
\end{tabular}

HP and MARINER show forecast superiority

Notes: bold = rejection of the null hypothesis.

Source: Author's calculations.

HP and MARINER show superior forecast accuracy in relation to other forecasts since the null of single forecast containing information from another individual forecast is rejected in this case. Thus, HP and MARINER can be used individually to forecast GDP future movement since they provide more accurate forecast (superiority) in relation to the combination of all forecasts. Forecast accuracy of the MARINER algorithm is not in a focus of this study leaving the issue of comprehensive forecast accuracy comparison for further research.

\section{Conclusions}

This study develops a new methodological framework for extracting long term component (trend) from GDP macroeconomic time series and analyzing business cycles. Proposed model successfully address two important issue using time series model in business cycles extraction: lack of proper economic interpretation and end of the sample drawback.

Results of a new method for extracting short and long term component developed in this study provide a complete economic interpretation behind the model. Long term component (trend) extracted using MARINER show a low frequency movement having permanent impact on output dynamics dependable on the synchronization moment between monetary and fiscal policy (policy synchronization regimes). Trend component identified using MARINER shows equilibrium GDP path with minimization of the output gap. In this way by eliminating the identified long term component it is possible to isolate a short and medium term stationary components. MARINER filter provide a reliable method of extracting long term component (trend) which can be used to isolate remaining short and 
medium term components in the series. Not only the proposed MARINER filter is reliable but is also based on a clear economic interpretation, i.e. business cycles in the economy arise as effect of faulty macroeconomic policy synchronization (poorly designed economic policy). Phillips (1962) in his seminal paper rightly point that policy makers cannot design successful economic policy without quantitative knowledge on the links between inflation, employment and growth. It is the lack or misunderstanding of this knowledge by policy makers to lead to inconsistent economic targets and policies and in the end business cycles. Results of the applied MARINER filter in this study support the conclusion put forward by Phillips (1962). MARINER contributes to the body of literature on business cycles by identifying macroeconomic policy synchronization issues as source of business cycles. Thus, fiscal and monetary policy have long term implications on output, employment and inflation and it is by adopting inconsistent macroeconomic goals that cycles are created.

In general, our results indicate that standard econometric filters fail to identify the long-term component (trend) from GDP series but a trend cycle component with a residual business cycles. Study results show that MARINER performs better in relation to other econometric filters for three reasons. First, it extracts a trend (and not trend cycle) component that provides an explicit indication of the future long term movements in outputs (GDP). Secondly, the extracted trend component is based on solid economic interpretation (theory). Finally, forecasting abilities of MARINER outperform the ones of standard econometric filters examined in this study. Standard econometric tests $\left(\mathrm{R}^{2}, \mathrm{AIC}\right.$, forecast ability) support the findings with MARINER filter performing better in extracting and forecasting long term trend component in the GDP series (see Table 2). Diebold-Mariano test (2002) test results (see Table 3) do not support the thesis of MARINER as superior econometric filters. However, forecast tests (see Table 4) and encompassing test of Chong and Hendry (1986), Timmermann (2006) support this thesis (see Table 5).

Our study indicates that poor macroeconomic policy synchronization causes business cycles. The thesis is supported by empirical results offered in this study. Considering these results, policy makers must put more effort on acquiring quantitative knowledge on the link between (un)employment, inflation and growth. It is only with this knowledge that they will be able to set up consistent economic policy objectives and design efficient economic policy. Whenever policy makers adopt inconsistent economic aims, derived economic policy is by default also inconsistent leading to business cycles. Consequently, future econometric filters must address this issue putting more emphasis on economic interpretation of the time series extracted components (particularly output series). Otherwise, business cycles will continue to be addressed as normal fluctuations in the economic activity while they are not. As Phillips (1962) and Škare (2010) correctly point out, adoption of inconsistent economic policy goals lead to design and realization of poor economic policy. It is the same inconsistent economic policy to cause a nationwide "schizophrenic" behavior of economic agents leading to harmful fluctuations in economic activity (business cycles). To prevent such harmful fluctuations and maybe even eliminate business cycles, policy makers must promptly address this issue. To do so, they must acknowledge the chance that it is the poor macroeconomic policy synchronization to cause economic fluctuations. This study provides strong empirical support that demands their prompt response in addressing this issue. 
Some limitations concerning empirical results of this study might be related to the one country analysis (Croatia) and data limitations to 2009. Further research using MARINER filter on a large sample and including the effects of the 2008 crisis is needed. For example, adding empirical results of MARINER filtering on larger sample could provide more insightful results on macroeconomic policy synchronization issue. Not only, it would provide much stronger empirical support of the thesis on poor macroeconomic policy synchronization as a source of business cycles. Another possible limitation lies in the output gap definition as defined by OECD statistics used in Škare (2010).

This study is our modest contribution to the business cycles body of literature hoping to motivate further research on econometric filters based on strong economic interpretation. Using results presented in this study as well as declared shortcomings, inspired researchers can move their focus of research on poor macroeconomic policy synchronization behind business cycles setting new econometric filters to address this issue. Further research testing MARINER robustness on macroeconomic data from other countries and region would help to overcome this study main limitations - a single country study. Based on our preliminary results for U.S. Economy (not presented here) using MARINER we are confident it will prove efficient in business cycles component extraction when applied under different economic structures and conditions but further research is needed.

\section{Acknowledgment}

This work has been fully supported by the Croatian Science Foundation under the project number 9481 Modelling Economic Growth - Advanced Sequencing and Forecasting Algorithm. Any opinions, findings, and conclusions or recommendations expressed in this material are those of the author(s) and do not necessarily reflect the views of Croatian Science Foundation.

\section{References}

Akaike, H. 1974. A new look at the statistical model identification, IEEE Automatic Transactions on Automatic Control 19(6): 716-723. https://doi.org/10.1109/TAC.1974.1100705

Basu, S. 1996. Procyclical productivity: increasing returns or cyclical utilization?, The Quarterly Journal of Economics 111(3): 719-751. https://doi.org/10.2307/2946670

Baxter, M.; King, R. G. 1999. Measuring business cycles: approximate band-pass filters for economic time series, Review of Economics and Statistics 81(4): 575-593. https://doi.org/10.1162/003465399558454

Bernanke, B. S. 1983. Irreversibility, uncertainty, and cyclical investment, The Quarterly Journal of Economics 98(1): 85-106. https://doi.org/10.2307/1885568

Bernanke, B. S.; Gertler, M.; Gilchrist, S. 1999. The financial accelerator in a quantitative business cycle framework, Handbook of Macroeconomics 1(Part C): 1341-1393.

https://doi.org/10.1016/S1574-0048(99)10034-X

Braun, R. A. 1994. Tax disturbances and real economic activity in the postwar United States, Journal of Monetary Economics 33(3): 441-462. https://doi.org/10.1016/0304-3932(94)90039-6

Burns, A. F; Mitchell, W. C. 1946. Measuring Business Cycles. NBER. 
Burnside, A. C.; Eichenbaum, M. S.; Rebelo, S. T. 1996. Sectoral Solow residuals, European Economic Review 40(3-5): 861-869. https://doi.org/10.1016/0014-2921(95)00095-X

Burnside, C.; Eichenbaum, M.; Rebelo, S. 1993. Labor hoarding and the business cycle, The Journal of Political Economy 101(2): 245-273. https://doi.org/10.1086/261875

Butterworth, S. 1930. On the theory of filter amplifiers, Experimental Wireless and the Wireless Engineer 7: 536-541.

Chong, Y. Y.; Hendry, D. F. 1986. Econometric evaluation of linear macro-economic models, The Review of Economic Studies 53(4): 671-690. https://doi.org/10.2307/2297611

Christiano, L. J.; Eichenbaum, M. 1992. Current real-business-cycle theories and aggregate labor-market fluctuations, The American Economic Review 82(2): 430-450.

Christiano, L. J.; Fitzgerald, T. J. 2003. The band pass filter, International Economic Review 44(2): 435465.

Clark, T. E.; McCracken, M. W. 2001. Tests of equal forecast accuracy and encompassing for nested models, Journal of Econometrics 105(1): 85-110. https://doi.org/10.1016/S0304-4076(01)00071-9

Cogley, T.; Nason, J. M. 1995. Effects of the Hodrick-Prescott filter on trend and difference stationary time series implications for business cycle research, Journal of Economic Dynamics and Control 19(1-2): 253-278. https://doi.org/10.1016/0165-1889(93)00781-X

Diebold, F. X.; Rudebusch, G. 1996. Measuring business cycles: a modern perspective, Review of Economics and Statistics 78(1): 67-77. https://doi.org/10.2307/2109848

Diebold, F. X.; Mariano, R. S. 2002. Comparing predictive accuracy, Journal of Business \& Economic Statistics 20(1): 134-144. https://doi.org/10.1198/073500102753410444

Dixit, A. K.; Stiglitz, J. E. 1977. Monopolistic competition and optimum product diversity, The American Economic Review 67(3): 297-308.

Evans, C. L. 1992. Productivity shocks and real business cycles, Journal of Monetary Economics 29(2): 191-208. https://doi.org/10.1016/0304-3932(92)90012-Q

Finn, M. G. 2000. Perfect competition and the effects of energy price increases on economic activity, Journal of Money, Credit and Banking 32(3): 400-416. https://doi.org/10.2307/2601172

Fisher, J. 2004. Technology Shocks Matter, in Econometric Society 2004 North American Winter Meetings 14, 3-5 January 2004, San Diego, California. Econometric Society.

Galí, J. 1999. Technology, employment, and the business cycle: do technology shocks explain aggregate fluctuations?, The American Economic Review 89(1): 249-271. https://doi.org/10.1257/aer.89.1.249

Hamilton, J. 2016. Why you should never use the Hodrick-Prescott filter. University of California, Working Paper.

Harvey, A. C. 1990. Forecasting, structural time series models and the Kalman filter. Cambridge University Press. https://doi.org/10.1017/CBO9781107049994

Harvey, D.; Leybourne, S.; Newbold, P. 1997. Testing the equality of prediction mean squared errors, International Journal of Forecasting 13(2): 281-291. https://doi.org/10.1016/S0169-2070(96)00719-4

Hodrick, R. J.; Prescott, E. C. 1997. Postwar U.S. business cycles: an empirical investigation, Journal of Money, Credit and Banking 29(1): 1-16. https://doi.org/10.2307/2953682

Jaimovich, N.; Floetotto, M. 2008. Firm dynamics, markup variations, and the business cycle, Journal of Monetary Economics 55(7): 1238-1252. https://doi.org/10.1016/j.jmoneco.2008.08.008

Keynes, J. M. 1936. The General Theory of Employment, Interest and Money. London: Macmillan Publishers.

Kendall, M. G. 1976. Time Series. $2^{\text {nd }}$ edition. London: Griffin \& Co.

Kim, I.-M.; Loungani, P. 1992. The role of energy in real business cycle models, Journal of Monetary Economics 29(2): 173-189. https://doi.org/10.1016/0304-3932(92)90011-P 
King, R. G.; Plosser, C. I.; Stock, J. H. 1991. Stochastic trends and economic fluctuations, The American Economic Review 81(4): 819-840.

King, R. G.; Rebelo, S. T. 1999. Resuscitating real business cycles, Chapter 14 in J. B. Taylor, M. Woodford (Eds.). Handbook of macroeconomics. Edition 1, Volume 1. Elsevier.

McGrattan, E. R. 1994. The macroeconomic effects of distortionary taxation, Journal of Monetary Economics 33(3): 573-601. https://doi.org/10.1016/0304-3932(94)90044-2

Mitchell, W. C. 1913. Business cycles. Berkeley: University of California Press.

Mitchell, W. C. 1927. Business cycles: the problem and its setting. NBER Books. National Bureau of Economic Research, Inc.

NBER Committee. 2012. U.S. Business cycle expansions and contractions [online], [ cited 20 October 2012]. Available from internet: http://www. nber. org/cycles. html

Nelson, C. R.; Plosser, C. R. 1982. Trends and random walks in macroeconomic time series: some evidence and implications, Journal of Monetary Economics 10(2): 139-162.

https://doi.org/10.1016/0304-3932(82)90012-5

Norrbin, S. C. 1993. The relation between price and marginal cost in U.S. industry: a contradiction, Journal of Political Economy 101(6): 1149-1164. https://doi.org/10.1086/261918

Phillips, A. W. 1958. The relation between unemployment and the rate of change of money wage rates in the United Kingdom, 1861-1957, Economica 25(100): 283-299.

https://doi.org/10.1111/j.1468-0335.1958.tb00003.x

Phillips, A. W. 1962. Employment, Inflation and Growth, Economica 29(113): 1-16. https://doi.org/10.1111/j.1468-0335.1962.tb00001.x

Pollock, D. 2000. Trend estimation and de-trending via rational square-wave filters, Journal of Econometrics 99(2): 317-334. https://doi.org/10.1016/S0304-4076(00)00028-2

Pollock, D. 2016. Econometric filters, Computational Economics 48(4): 669-691. https://doi.org/10.1007/s10614-015-9543-2

Prescott, E. C. 1986. Theory ahead of business-cycle measurement, Carnegie-Rochester Conference Series on Public Policy 25: 11-44. https://doi.org/10.1016/0167-2231(86)90035-7

Punzo, L. F. 2015. Cycles, growth and structural change. New York: Routledge.

Ramey, V. A.; Shapiro, M. D. 1998. Costly capital reallocation and the effects of government spending, Carnegie-Rochester Conference Series on Public Policy 48(1): 145-194. https://doi.org/10.1016/S0167-2231(98)00020-7

Rašić Bakarić, I.; Tkalec, M.; Vizek, M. 2016. Constructing a composite coincident indicator for a posttransition country, Economic Research-Ekonomska Istraživanja 29(1): 434-445.

Romer, C. D. 1999. Changes in business cycles: evidence and explanations, Journal of Economic Perspectives 13(2): 23-44. https://doi.org/10.1257/jep.13.2.23

Rotemberg, J. J.; Woodford, M. 1996. Real-business-cycle models and the forecastable movements in output, hours, and consumption, The American Economic Review 86(1): 71-89.

Singleton, K. J. 1988. Econometric issues in the analysis of equilibrium business cycle models, Journal of Monetary Economics 21(2-3): 361-386. https://doi.org/10.1016/0304-3932(88)90036-0

Škare, M. 2010. Can there be a "golden triangle" of internal equilibrium?, Journal of Policy Modeling 32(4): 562-573. https://doi.org/10.1016/j.jpolmod.2010.05.005

Skare, M.; Stjepanović, S. 2015. Measuring business cycles: a review, Contemporary Economics 10(1): 83-94.

Sodeyfi, S.; Katircioglu, S. 2016. Interactions between business conditions, economic growth and crude oil prices, Economic Research-Ekonomska istraživanja 29(1): 980-990.

https://doi.org/10.1080/1331677X.2016.1235504 
Stock, J. H.; Watson, M. W. 1988. Testing for common trends, Journal of the American Statistical Association 83(404): 1097-1107. https://doi.org/10.1080/01621459.1988.10478707

Stock, J. H.; Watson, M. W. 2003. Has the business cycle changed and why?, NBER Macroeconomics Annual 17: 159-230. https://doi.org/10.1086/ma.17.3585284

Timmermann, A. 2006. Forecast combinations, Chapter 4 in G. Elliott, C. W. J. Granger, A. Timmermann (Eds.). Handbook of economic forecasting. Elsevier, 135-196. https://doi.org/10.1016/S1574-0706(05)01004-9

Zarnowitz, V. 1992a. Business cycles: theory, history, indicators, and forecasting. Chicago: The University of Chicago Press. https://doi.org/10.7208/chicago/9780226978925.001.0001

Zarnowitz, V. 1992b. What is a business cycle? In M. T. Belongia, M. R. Garfinkel (Eds). The business cycle: theories and evidence. Springer Netherlands. https://doi.org/10.1007/978-94-011-2956-5_1

Marinko SKARE, PhD, is Professor of Economics, Economic Research Journal Editor in Chief, Member of Editorial Board of several international journals, Department Economics and Tourism "Dr. Mijo Mirković" in Pula, Juraj Dobrila University of Pula. He served as Assistant Dean for Education, Faculty of Economics \& Tourism, Pula, Assistant Dean for International Cooperation, Faculty of Economics \& Tourism, Pula, Main and Team Researcher on several scientific projects, Former Dean of the Faculty of Economics \& Tourism, Pula and Former Vice President for International Cooperation, Juraj Dobrila University of Pula. He has published several books and a large number of scientific papers on the subject of economic growth, welfare economics and poverty, human capital, economics in transition, economic philosophy and monetary economics. 